\title{
Classical swine fever virus induces oxidative stress in swine umbilical vein endothelial cells
}

\author{
Lei He ${ }^{1,2}$, Yanming Zhang ${ }^{1 *}$, Yanqin Fang ${ }^{1}$, Wulong Liang ${ }^{1}$, Jihui Lin ${ }^{1}$ and Min Cheng ${ }^{1}$
}

\begin{abstract}
Background: Classical swine fever virus (CSFV) infection causes significant losses of pigs, which is characterized by hemorrhage, disseminated intravascular coagulation and leucopenia. The swine vascular endothelial cell is a primary target cell for CSFV. The aim of this study was to determine the role of CSFV infection in inducing oxidative stress (OS) in vascular endothelial cells.

Results: We demonstrated that CSFV infection induced oxidative stress in swine umbilical vein endothelial cells (SUVECs), characterized by the induction of reactive oxygen species (ROS) production and the elevations of porcine antioxidant proteins thioredoxin (Trx), peroxiredoxin-6 (PRDX-6) and heme oxygenase-1 (HO-1) expression. Furthermore, cyclooxygenase-2 (COX-2), a pro-inflammatory protein related to oxidative stress, was up-regulated while anti-inflammatory protein peroxisome proliferator-activated receptor- $\gamma$ (PPAR- $\gamma$ ), an important mediator in vascular functional regulation, was down-regulated in the CSFV infected cells. In addition, antioxidants showed significant inhibitory effects on the CSFV replication, indicating a close relationship between CSFV replication and OS induced in the host cells.
\end{abstract}

Conclusions: Our results indicated that CSFV infection induced oxidative stress in SUVECs. These findings provide novel information on the mechanism by which CSFV can alter intracellular events associated with the viral infection.

Keywords: Classical swine fever virus, Oxidative stress, Antioxidant protein, Reactive oxygen species, Inflammatory response

\section{Background}

Classical swine fever virus (CSFV), the etiological agent of Classical swine fever (CSF) occurring worldwide, belongs to Pestivirus genus of the Flaviviridae family [1]. The frequent appearance of CSFV infections across national borders and the considerable socio-economic impact on the pig industry make CSF a notifiable (previously list A) disease by the World Organization for Animal Health (OIE) [2]. The infection of pigs with CSFV strains of high virulence such as shimen strain causes a severe acute disease with high mortality rate, characterized by haemorrhagic diathesis, leucopenia, thrombocytopenia and disseminated intravascular coagulation [3,4]. Since 1990, CSF has been eradicated in many areas of the world through a 'stamping-out' slaughter policy. However, the epizootic outbreaks caused considerable financial and

\footnotetext{
*Correspondence: yanmingzhang76@yahoo.com

${ }^{1}$ College of Veterinary Medicine, Northwest A \& F University, Yangling, Shaanxi 712100, P.R. China

Full list of author information is available at the end of the article
}

sociological impact, and increasing public opposition against stamping-out policies has now led to an increased attention for new vaccines and therapies $[5,6]$. By now, the pathogenesis of CSFV is still not fully understood and no cure for CSF is presently available apart from symptomatic treatment. Elucidating the mechanism of CSFV pathogenesis will provide new therapeutic targets to treat CSFV infection and its complications.

There is increasing evidence supporting the view that oxidative stress, a deleterious action represented by the elevation of ROS, might play a critical role in the pathophysiology of virus infection $[7,8]$. Oxidative stress has been implicated in the pathogenesis of various seemingly unrelated viruses, e.g., human immunodeficiency virus [9], human rhinovirus [10], bovine diarrhea virus [11], and hepatitis $C$ virus $[12,13]$. However, whether oxidative stress occurs on CSFV infected endothelial cells is still unknown, and little information is available on its role in CSFV multiplication. Mounting evidence has emphasized that vascular 
oxidative stress and increased production of ROS contribute to the mechanism of vascular dysfunction, while it was reported that blood vessel dysfunction plays an important role in the pathogenesis of CSFV [14]. One intriguing possibility is that CSFV through its effect on oxidative stress plays a pathophysiological role in vascular dysfunction. Interestingly, the bioavailability of nitric oxide (NO), a dominant factor responsible for regulating vascular function, was found to be reduced in CSFV infected vascular endothelial cells [15]. And it was also reported to be decreased when oxidative stress and the aberrant expression of ROS occurred [16].

Here, we demonstrated that CSFV infection induced oxidative stress in SUVECs, characterized by the induction of ROS production and associated with the elevations of antioxidant proteins Trx, PRDX-6 and HO-1 expression. Further studies showed that inflammatory related proteins COX-2 and PPAR- $\gamma$ were also altered in the CSFV infected cells. It was worth noting that antioxidants showed significant inhibitory effects on the CSFV replication, indicating a close relationship between CSFV replication and OS induced in the host cells. The results of these findings have potentially important implications for the mechanism by which CSFV can alter intracellular events associated with the viral infection and the controlling this economically important animal disease.

\section{Results}

\section{CSFV induces ROS production in SUVECs}

The production of ROS, a representative of oxidative stress, was investigated after the infection of CSFV in the SUVECs at 24, 48 and $72 \mathrm{~h}$ respectively. Dihydroethidium (DHE) can be oxidized to ethidium by ROS. Ethidium is known to be free to intercalate with DNA in the nucleus, where it emits fluorescence at $605 \mathrm{~nm}$. So in this study, the level of ROS was measured in two ways: fluorescence microscopy and flow cytometry by incubating with DHE. As shown in Figure 1, more cells were dyed red in the CSFV infected cells, indicating that ROS levels were higher compared to the control SUVECs. The level of ROS was increased with prolong cultured time as the level of ROS in SUVECs infected with CSFV at $72 \mathrm{~h}$ was significantly higher than $48 \mathrm{~h}$ and $24 \mathrm{~h}$. To confirm this observation, the flow cytometry was carried out and results described in Figure 2 clearly show the proportions of cells stained with DHE for CSFV infected cells at 24, 48, and $72 \mathrm{~h}$ were $13.2 \pm 1.516,21.0 \pm 2.832$, and $24.2 \pm 3.732$ respectively, while for the control cells was $7.1 \pm 0.566$. It indicated that the production of ROS was increased in CSFV infected cells by a greater extent as compared to the control SUVECs. Furthermore, the ROS levels were also measured by the cell superoxide anion in situ assay. The average values of optical density (OD) at a wavelength of $650 \mathrm{~nm}$ per sample were used for statistical analyses. As shown in Figure 3, the CSFV infected cells produced much more ROS leading to a significantly higher in OD values (Figure 3). Taken together, these data suggested that the infection of CSFV is associated with a markedly enhanced expression level of ROS.

\section{CSFV infection induces elevations of porcine antioxidant proteins expression}

Antioxidant genes' expression are regulated by the delicate balance between the levels of oxidizing and reducing equivalents of the redox state [17], and the activation of antioxidant proteins is associated with oxidative stress during the viral infection $[13,18]$. In this assay, the antioxidant proteins thioredoxin (Trx), peroxiredoxin-6 (PRDX6) and heme oxygenase-1 (HO-1) were examined at 24, 48 and $72 \mathrm{~h}$ post-infection. As shown in Figure 4, we found that the mRNA levels of Trx, PRDX-6 and HO- 1 were elevated in CSFV infected cells compared to the control cells. Especially, the levels of Trx and PRDX-6 were significantly higher at $72 \mathrm{~h}$ post infection, approximately 15 -fold higher than in the control SUVECs, and the elevations showed a time-dependent manner after the CSFV infection. The mRNA levels of HO-1 were slightly elevated compared with the controls. These results clearly suggested that CSFV alters the mRNA levels of antioxidants in the SUVEC cells in different levels.

\section{CSFV infection induces a pro-inflammatory effect on SUVEC}

Studies have shown that oxidative stress and the inflammation have major roles in vascular diseases. We further examined the effect of CSFV infection on peroxisome proliferator-activated receptor- $\gamma$ (PPAR- $\gamma$ ) and Cyclooxygenase-2 (COX-2) which are highly expressed in vascular endothelial cells and correlated with both the increased reactive oxygen species (ROS) and the inflammatory response [8]. COX-2 induction in CSFV infected cell was evaluated by quantitative real-time RTPCR and western blot. CSFV infection could induce an increase on COX-2 mRNA and protein expression as shown in Figure 5A, B, respectively, indicating a role for CSFV in COX-2 induction. To further demonstrate the relationship between CSFV infection and the inflammatory effect, we also examined the alternation of PPAR- $\gamma$, which is an anti-inflammatory protein highly expressed in vascular endothelial cells. Quantitative real-time RT-PCR showed that the expression of PPAR- $\gamma$ in cells infected with CSFV was 5- to 6- fold lower compared with control cells (Figure 6). These observations suggest that the CSFV induces a significant pro-inflammatory effect on SUVECs.

Inhibitory effects of antioxidants on CSFV viral production To determine whether the oxidative stress induced by CSFV infection is involved in the viral replication or not, 


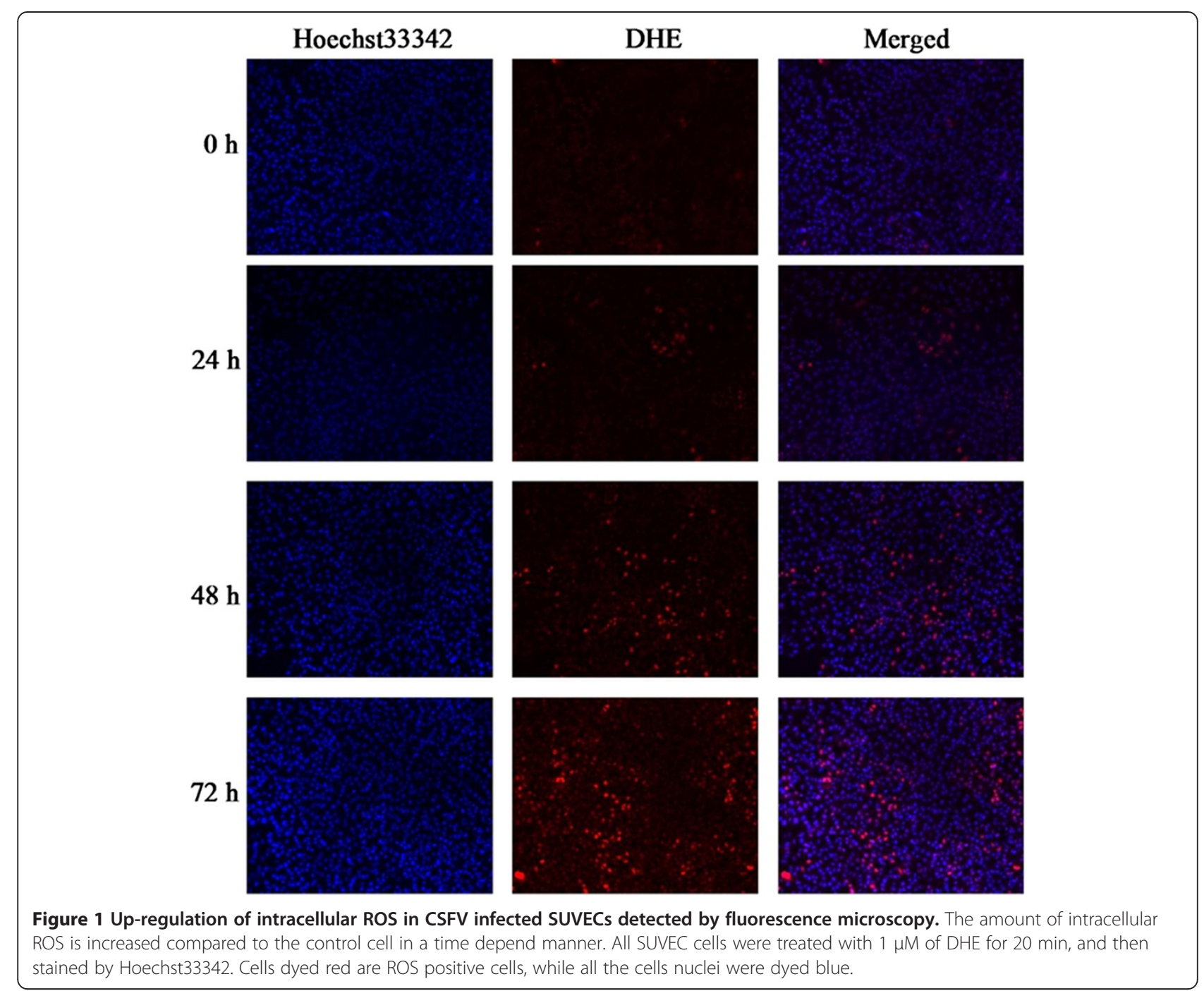

oxidative stress inhibitors glutathione (GSH), N-acetylL-cysteine (NAC), butylated hydroxyanisole (BHA) and curcumin, which were reported to counteract the oxygen free radical, were added to the CSFV infected cells. Quantitative real-time RT-PCR was carried out by using the lysates prepared from SUVECs, SUVECs infected with CSFV and CSFV infected cells incubated with GSH, NAC, BHA and curcumin and the COX-2 inhibitor aspirin (ASA) for $72 \mathrm{~h}$, respectively. Results showed that the amount of viral RNA was significantly reduced in

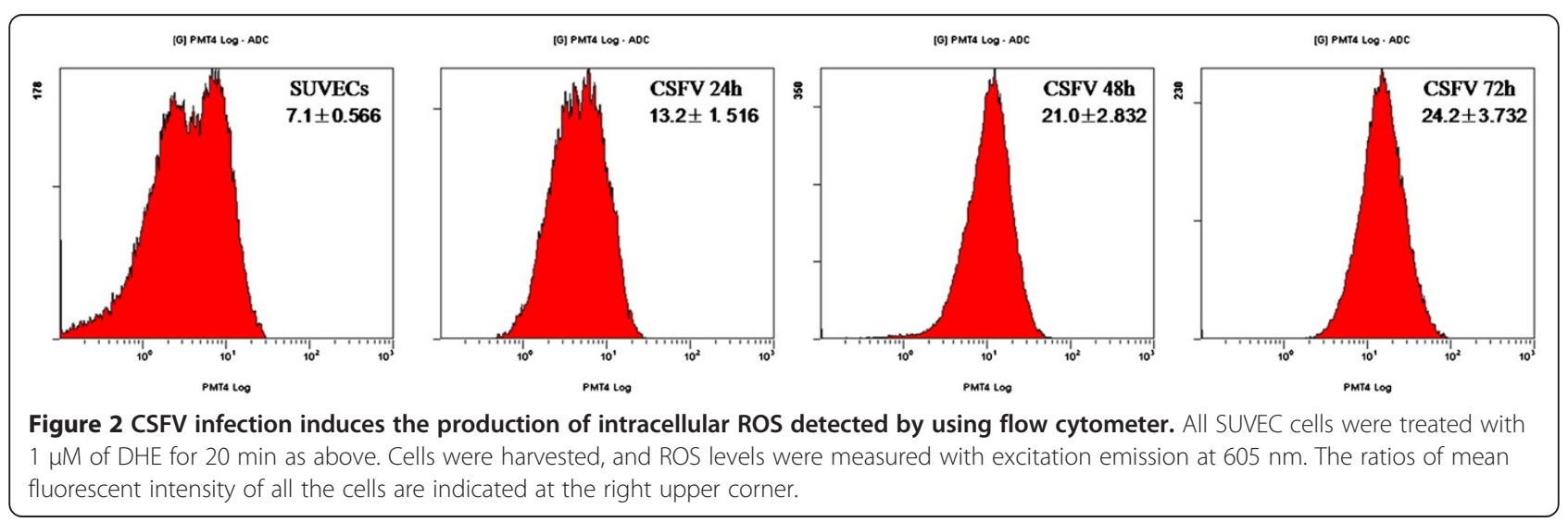




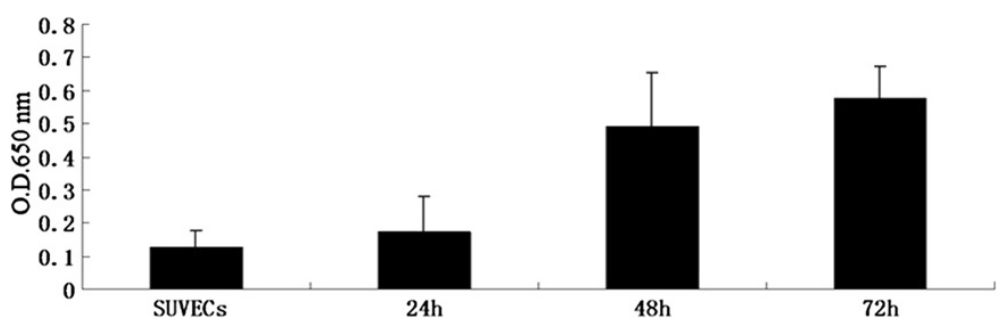

Figure 3 CSFV infection induces the production of intracellular ROS detected by using superoxide anion in-situ assay. All the cells were dealt following the instructions to evaluate the ROS level of each sample. OD650 values represent the mean \pm SD of three separate experiments performed three times.

the presence of antioxidants in varying degrees (Figure 7), indicating a close association between oxidative stress induced by CSFV and viral replication.

\section{Discussion}

The results from this present study provide evidence that CSFV infection induces oxidative stress and proinflammatory response in SUVEC cells and that the inhibition of oxidative stress may significantly decrease viral replication, indicating that oxidative stress is an important factor in CSFV growth in SUVEC cells.

CSFV is found to be highly susceptible to infect vascular endothelial cells [14]. The CSFV replication did not cause direct damage to the vascular endothelial cells; the cell morphology was normal and no CPE or plaque formation was induced in the infected cells [19]. However, the physiological function of vascular endothelial cells (VECs) was remarkably changed post infection $[14,15,20]$. It was found that vascular endothelial cells infected with CSFV induce tissue factor expression and inhibit apoptosis and interferon synthesis, which may lead to the establishment of long-term infection [14]. In this study, we showed for the first time that the CSFV infection could change the ROS level and the cellular redox state condition in CSFV infected cells, which may be related to the hemorrhaging found in the CSFV infected pigs as it has been suggested that the secretion of ROS from endothelial cells disrupts the haemostatic balance, leading to throm bocytopenia and platelet aggregation followed by haemorrhagic fever [21,22].

Reactive oxygen species (ROS) are produced as a consequence of normal metabolism, which is a double sword depending on their concentration [23,24]. Excess ROS induce oxidative modification of cellular molecules, activate or inhibit protein function, and promote proinflammatory factors' expression $[25,26]$. Our current observation shows that CSFV infection induces ROS in a time dependent manner. In lines with our finding, the down-regulation of $\mathrm{NO}$ production and attenuation of the expression of NO synthase in the CSFV infected porcine macrophages and aortic endothelial cells have been reported [15]. The concentrations of ROS reduce bioactive NO through chemical inactivation, forming toxic peroxynitrite, which in turn can uncouple endothelial NO synthase to form a dysfunctional superoxide-generating enzyme that contributes further to oxidative stress $[27,28]$. NO is reported to play a key role in vascular responses, such as the capability of leukocytes to adhere to the endothelium, the aggregation of platelets, angiogenesis and the relaxation of vascular smooth muscle cells $[29,30]$. Therefore, it is tempting to conclude that CSFV induces ROS production, which then inactivates the NO synthase and NO bioavailability results in blood vessel endothelial cells dysfunction.

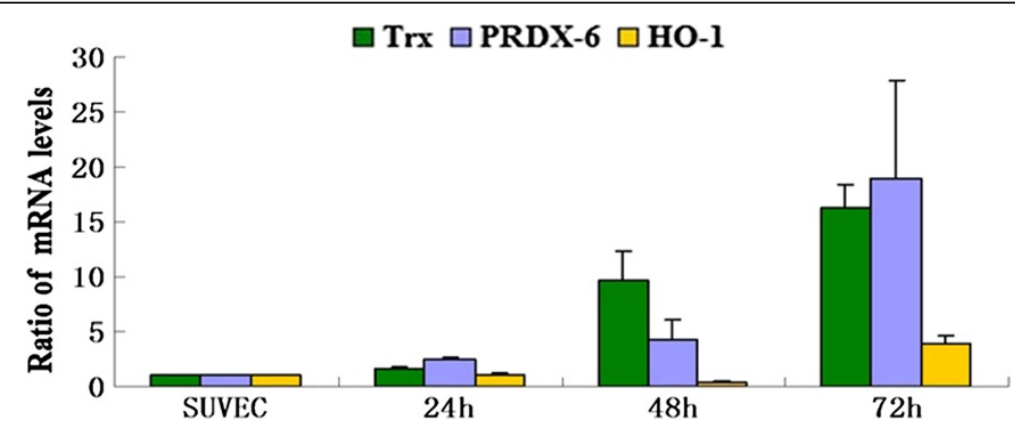

Figure 4 Effects of CSFV infection on porcine Trx, PRDX-6, and HO-1 expressions in cultured SUVEC cells. Quantitative real-time RT-PCR analysis of these antioxidant proteins' mRNA levels was normalized to the corresponding CT value for porcine $\beta$-actin mRNA. The basal expression level in SUVEC cells was assigned a value of 1 for each experiment. The data set represents the mean \pm SD of experiments repeated three times. 

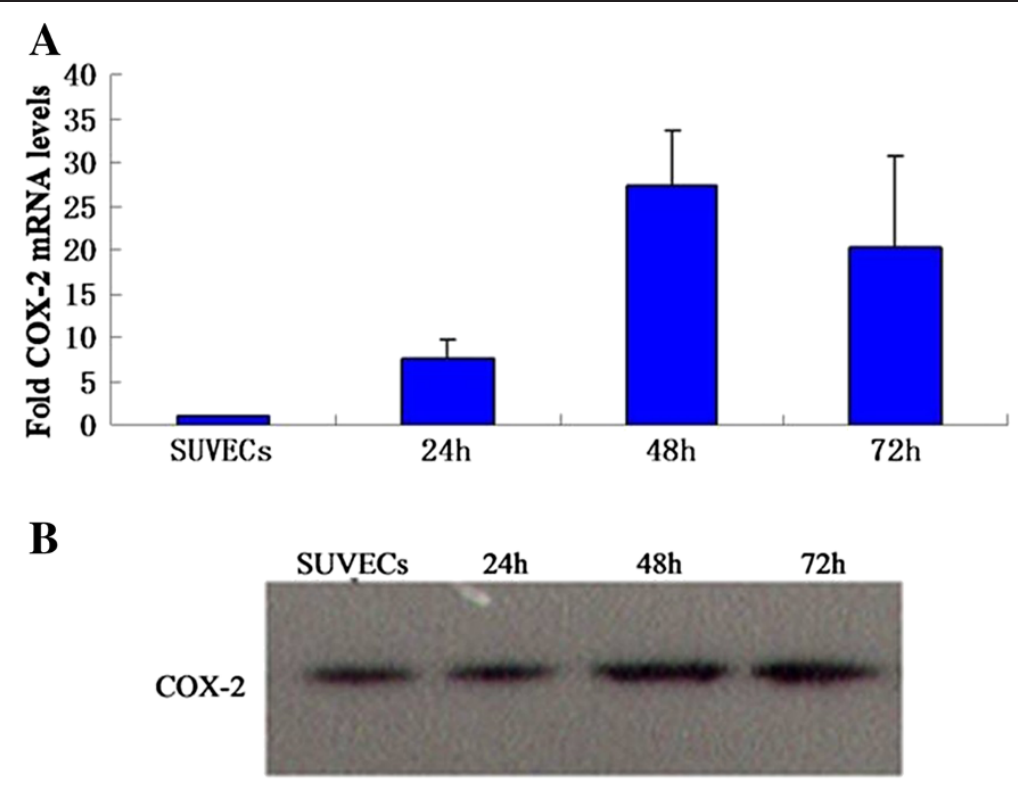

GAPDH

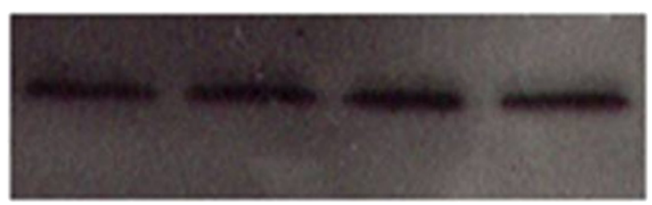

Figure 5 The effect of CSFV infection on porcine COX-2 expression in cultured SUVEC cells. (A) Quantitative real-time RT-PCR analysis of COX-2 levels was normalized to the corresponding $C T$ value for porcine $\beta$-actin mRNA. (B) The level of COX-2 expression was determined by western blot in CSFV infected cells at different points of time.

Modulating superoxide metabolism is one form of defense against excessive ROS production. The antioxidant enzyme Trx PRDX- 6 and HO-1 were reported to play critical roles in the clearance of ROS [31-33]. Our results have shown that Trx PRDX-6 and HO-1, which catalyses ROS into water and oxygen, were increased in the CSFV infected cells, indicating that the up-regulation of anti-oxidative stress proteins in host cells as a mechanism to relieve cellular oxidative stress induced by CSFV infection. It is notably to see that $\operatorname{Trx}$ is also a known anti-apoptotic factor in endothelial cells [34], and CSFV was reported to protect aortic endothelial cells from pIpC-mediated apoptosis [20].
However, whether the elevation of Trx contributes to the anti-apoptosis effect induced by CSFV infection needs more exploration.

Oxidative stress has been shown to participate in the modulation of inflammatory responses of the many pathological states [35,36]. Cyclooxygenase -2 (COX-2), a major pro-inflammatory mediator, and PPAR- $\gamma$, an anti-inflammatory agent, have been evaluated after the infection of CSFV. The up-regulation of COX-2 and down-regulating of PPAR- $\gamma$ have been observed. These results indicated that CSFV infection play a significant role in inducing inflammation. This observation is

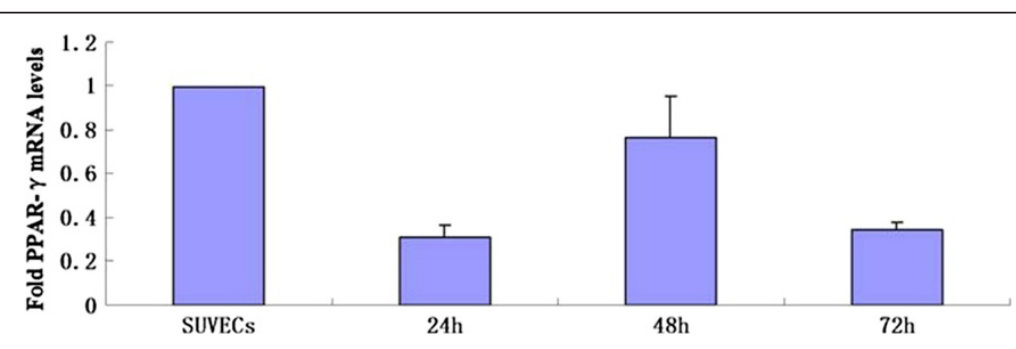

Figure 6 The effect of CSFV infection on porcine PPAR- $y$ expression in cultured SUVEC cells. Quantitative real-time RT-PCR analysis of PPAR- $y$ levels was normalized to the corresponding CT value for porcine $\beta$-actin mRNA. The basal expression level in SUVEC cells was assigned a value of 1 for each experiment. The data set represents the mean \pm SD of experiments repeated three times. 


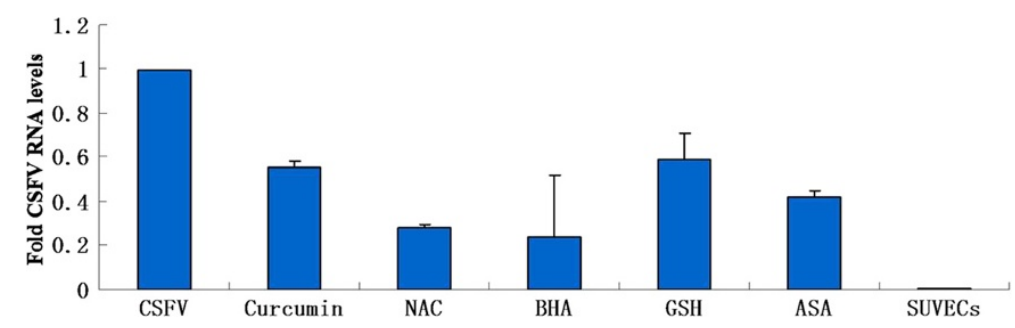

Figure 7 Inhibition of CSFV RNA replication by antioxidants in cultured SUVEC cells. The amount of viral genome was measured by real-time RT-PCR, which was normalized to the corresponding $\beta$-actin in the same sample. The mean of three repeat experiments performed in triplicate is shown, and error bars represent the SD.

consistent with a previous finding that CSFV could stimulate the expression of a number of proinflammatory cytokines in endothelial cells [37]. Importantly, the viral RNA replication was reduced by adding COX-2 inhibitor ASA, indicating the elevated level of this protein apparently facilitates the production of virus replication. Other researcher has found that the viral proteins, like NS3, core and NS5A proteins of $\mathrm{HCV}$ could activate the production of COX-2. And it has been shown that inactivation of COX-2 was associated with the inhibition of HCV RNA replication [38]. To investigate whether oxidative stress was required by CSFV during replication, Antioxidants PDTC, GSH and NAC were added to the CSFV-infected cells. The RNA level of CSFV infected cells were measured by Real time RT-PCR. The RNA replications of CSFV were reduced in varying degrees, indicating that oxidative stress may be important factor for the virus replication cycle. Consistently, oxidative stress and the inhibitory effect of antioxidants were also observed during different types of viral infections $[9,10,39]$. However, the present study only investigated the relationship between the viral replication and oxidative stress preliminarily, more studies about antioxidants-mediated inhibition against CSFV replication will be performed in near future.

\section{Conclusions}

In summary, the present results showed that CSFV infection induced oxidative stress by altering host intracellular ROS level and antioxidant status, accompanied with an increase in COX-2 and a reduction of PPAR- $\gamma$, contributing to the CSFV induced pro-inflammatory response and vascular dysfunction. The supplemental antioxidants significantly inhibited the viral replication. This study provided novel findings for understanding the molecular mechanisms of CSFV pathogenesis.

\section{Methods}

\section{Virus and cell culture}

Virulent CSFV (shimen strain) was provided by the Control Institute of Veterinary Bio-products and Pharmaceuticals (China) and propagated in the pig kidney cell line PK-15 cells. PK-15 cells were maintained in Dulbecco's modified Eagle's medium (DMEM; GIBCO, UK) supplemented with $10 \%$ heat-inactivated fetal calf serum (FCS) (Hyclone, China). The established swine umbilical vein endothelial cell line (SUVEC) was cultured as previously described [40]. Briefly, SUVEC cells were cultured at $37^{\circ} \mathrm{C}$ and $5 \%$ $\mathrm{CO}_{2}$ in DMEM containing 10\% FCS, $50 \mu \mathrm{g} / \mathrm{mL}$ heparin (Sigma-Aldrich, USA), and antibiotics $(100 \mu \mathrm{g} / \mathrm{mL}$ streptomycin and $100 \mathrm{U} / \mathrm{mL}$ penicillin). The culture medium was replaced every 3 days. All the experiments were approved in accordance with the guidelines of the committee for the Ethics on Animal Care and Experiments at Northwest Agriculture \& Forestry University.

\section{Viral infection}

One day before infection, SUVECs were seeded onto 6well culture plates at a concentration of $2 \times 10^{5}$ cells per well. To infect cells with CSFV, SUVECs $(30-50 \%$ confluency) were washed twice with PBS and adsorbed with CSFV at a multiplicity of infection (MOI) of 5 for $90 \mathrm{~min}$ at $37^{\circ} \mathrm{C}$. For control mock-infected cells, an equal amount of uninfected PK-15 cell lysate or PBS was added. The viral inoculum was then removed and the cell monolayers were washed three times with serumfree medium and replaced with DMEM containing 3\% FBS. The culture plates were incubated at $37^{\circ} \mathrm{C}$ with $5 \%$ $\mathrm{CO}_{2}$ in the humidified incubator.

The effect of GSH, NAC, BHA and curcumin on the amount of virus generated from infected SUVEC cells was examined by applying antioxidants in non-cytotoxic concentrations $(50 \mu \mathrm{M}$ GSH, $30 \mu \mathrm{M}$ NAC, $300 \mu \mathrm{M}$ $\mathrm{BHA}$, and $60 \mu \mathrm{M}$ curcumin, respectively) and the COX2 inhibitor aspirin $(10 \mu \mathrm{M}$ ASA) after CSFV infection. The effect of these inhibitors on CSFV viral production was observed by Quantitative real-time RT-PCR.

\section{Fluorescence microscopy}

As cellular superoxide especially ROS production could be assessed by oxidation of dihyroethidium (DHE) to ethidium. And the conversion of DHE to ethidium results in red nuclear fluorescence. Alteration of ROS in CSFV infected SUVECs at 24, 48 and $72 \mathrm{~h}$ post-infection were 
Table 1 Host gene and CSFV RNA analyzed and primer sets for real-time RT-PCR

\begin{tabular}{|c|c|c|c|}
\hline Genes & Forward primer & Reverse primer & Product length (bp) \\
\hline Trx & 5'- CAAAGTATTCCAATGTCGTGTTCC-3' & $5^{\prime}$ - AGTTCACCCACCTTCTGTCCC -3' & 127 \\
\hline PRDX-6 & $5^{\prime}$-GTGAGGAGCCCAAGGAAACG-3' & $5^{\prime}$ - CCCAACTGGATGGCAAGGTC-3' & 73 \\
\hline $\mathrm{HO}-1$ & 5'-GTCCTCAAGAAGATTGCTCAGAAG-3' & 5'-GTCATCTCCAGAGTGTTCATTCG-3' & 140 \\
\hline $\operatorname{cox}-2$ & 5' -CTTCCTCCTGTGCCTGATGACTG-3' & 5'-GGTCCTCGCTTCTGATCTGTCTTG-3' & 200 \\
\hline PPAR- $\gamma$ & 5'-TGACAGGAAAGACCACAGACAAAT-3' & 5'-GGGTGATGTGTTTGAACTTGATT-3' & 96 \\
\hline CSFV & 5'- TCAACCGAAGAAATGGGAGATG-3' & $5^{\prime}$ - TCCACCCTATTGGGCAGACA-3' & 133 \\
\hline$\beta$-actin & $5^{\prime}$-CGTCCACCGCAAATGCTTC-3' & $5^{\prime}$-AACCGACTGCTGTCACCTTCAC-3' & 217 \\
\hline
\end{tabular}

detected by using fluorescence microscopy, SUVECs were washed with Hank's balanced salt solution (HBSS) and incubated with Hoechst $33342(10 \mathrm{ng} / \mathrm{mL})$ at $37^{\circ} \mathrm{C}$ for $15 \mathrm{~min}$, and then washed three time with HBSS. SUVECs were incubated with DHE $(2 \mu \mathrm{M}$; Beyotime, China) at $37^{\circ} \mathrm{C}$ for $20 \mathrm{~min}$ and washed with DMEM without serum. Then the cell images were viewed by fluorescence microscopy (Nikon, Japan).

\section{Flow cytometry}

Alteration of ROS in CSFV infected SUVECs at 0, 24, 48 and $72 \mathrm{~h}$ post-infection were also measured by using flow cytometry, SUVECs were incubated with DHE (2 $\mathrm{MM}$; Beyotime, China) for $20 \mathrm{~min}$, and harvested in DMEM of $5 \%$ FBS. After being washed two times with PBS, cells finally were suspended in $1 \mathrm{~mL}$ of PBS. Superoxide levels were determined by using a Coulter Epics XL flow cytometer with an excitation emission at $605 \mathrm{~nm}$.

\section{Quantitative real-time RT-PCR}

Total RNA was isolated from SUVECs infected with CSFV at 0, 24, 48 and $72 \mathrm{~h}$ post-infection by using Trizol reagent (Invitrogen, USA) according to the manufacturer's protocol and was removed contaminating genomic DNA by being subjected to DNase treatment with RNase-free DNase (Takara Bio, Dalian, China). The cDNA was reverse transcribed from $1 \mu \mathrm{g}$ of total RNA by using RT primer mix (Takara Bio, Dalian, China). Primers for genes of interest and the housekeeping gene $\beta$-actin, whose sequences are shown in Table 1 , were designed by using Beacon Designer software program. Quantitative PCR was carried out by using a SYBR ExScript $^{\mathrm{TM}}$ RT-PCR Kit (Takara Bio, Dalian, China), according to manufacturer's instructions. Reactions were performed in an iQ5 Real-Time PCR Detection System (Bio-Rad, USA) under the following conditions: $10 \mathrm{~min}$ at $95^{\circ} \mathrm{C}$ (heat inactivation of reverse transcriptase and activation of taq polymerase), and 42 cycles of $5 \mathrm{~s}$ at $95^{\circ} \mathrm{C}, 10 \mathrm{~s}$ at $58^{\circ} \mathrm{C}$, and $15 \mathrm{~s}$ at $72^{\circ} \mathrm{C}$ (PCR amplification). Data were analyzed according to the Comparative threshold $(\mathrm{Ct})$ method, where the amount of RNA in samples normalized to $\beta$-actin and the tests was determined in triplicate.

\section{Western blot}

The SUVECs extracts were prepared by washing cells with PBS, harvested by scraping and then suspended in $1 \mathrm{~mL}$ PBS. After clarification by centrifugation at 3 $000 \mathrm{~g}$ for $5 \mathrm{~min}$ at $4^{\circ} \mathrm{C}$, the cells were resuspended in cell lysis buffer $(50 \mathrm{mM}$ Tris- $\mathrm{HCl}, 5 \mathrm{mM}$ EDTA, $150 \mathrm{mM}$ $\mathrm{NaCl}, 0.1 \%$ NP-40, 0.5\% deoxycholic acid, $1 \mathrm{mM}$ sodium orthovanadate, $100 \mu \mathrm{g} / \mathrm{mL}$ PMSF and protease inhibitors) and centrifuged at $15000 \mathrm{~g}$ for $30 \mathrm{~min}$ at $4{ }^{\circ} \mathrm{C}$. Equal amounts of total protein $(15 \mu \mathrm{g} /$ lane $)$ were separated by $12 \%$ sodium dodecyl sulphate polyacrylamide gel electrophoresis (SDS-PAGE) and transferred onto a 0.2-mm PVDF membrane (Millipore, USA) using a TransBlot SemiDry transfer device (BioRad). Membranes were blocked for $1 \mathrm{~h}$ at room temperature with 5\% skim milk in TBST buffer [20 mM Tris- $\mathrm{HCl}(\mathrm{pH} 7.5), 50 \mathrm{mM} \mathrm{NaCl}$, and $0.05 \%$ Tween 20]. For immunodetection, the membranes were incubated with mouse anti-COX-2 (Abcam, UK) or mouse anti-porcine GAPDH (Genscript, USA) antibody overnight at $4^{\circ} \mathrm{C}$ with $5 \%$ skim milk in TBST buffer and incubated at $37^{\circ} \mathrm{C}$ with horseradish peroxidaseconjugated goat anti-rabbit antibody for $1 \mathrm{~h}$ at $37^{\circ} \mathrm{C}$. Between each incubation step, membranes were washed with TBST buffer. The protein bands were visualized by enhanced chemiluminescence methods as per the manufacturer's instructions (Millipore, USA).

\begin{abstract}
Abbreviations
CSFV: Classical swine fever virus; OS: Oxidative stress; SUVECs: Swine umbilical vein endothelial cells; VECs: Vascular endothelial cells; ROS: Reactive oxygen species; Trx: Thioredoxin; PRDX-6: Peroxiredoxin-6; HO-1: Heme oxygenase-1; COX-2: Cyclooxygenase-2; PPAR- $\gamma$ : Peroxisome proliferator-activated receptor- $\gamma$; NO: Nitric oxide; GSH: Glutathione; NAC: N-acetyl-L-cysteine; BHA: Butylated hydroxyanisole; ASA: Aspirin; FCS: Fetal calf serum; HBSS: Hank's balanced salt solution.
\end{abstract}

\section{Competing interests}

The authors declare that they have no competing interests.

\section{Authors' contributions}

$\mathrm{LH}$ took part in all the experiments, and wrote the manuscript. YMZ designed all the experiments. YQF participated in the cell culture and virus infection. WLL and $\mathrm{JHL}$ participated in Western blot detection and carried out and quantitative real-time RT-PCR. MC made a major contribution to the fluorescence microscopy. All authors have read and approved the final manuscript. 


\section{Acknowledgements}

This work was supported by the National Natural Science Foundation of China (No. 31172339). We express our appreciation to Ph.D. Kai Kang, Da-hui Wang for their technical assistance.

\section{Author details}

${ }^{1}$ College of Veterinary Medicine, Northwest A \& F University, Yangling, Shaanxi 712100, P.R. China. ${ }^{2}$ Animal Disease and Public Security Academician Workstation of Henan province, The Key Lab of Animal Disease and Public security, Henan University of Science and Technology, Luoyang 471003, P.R. China.

Received: 11 July 2014 Accepted: 11 November 2014

Published online: 02 December 2014

\section{References}

1. Tang QH, Zhang YM, Xu YZ, He L, Dai C, Sun P: Up-regulation of integrin beta3 expression in porcine vascular endothelial cells cultured in vitro by classical swine fever virus. Vet Immunol Immunopathol 2010, 133(2-4):237-242.

2. Dreier S, Zimmermann B, Moennig V, Greiser-Wilke I: A sequence database allowing automated genotyping of Classical swine fever virus isolates. J Virol Methods 2007, 140(1-2):95-99.

3. He L, Zhang YM, Lin Z, Li WW, Wang J, Li HL: Classical swine fever virus NS5A protein localizes to endoplasmic reticulum and induces oxidative stress in vascular endothelial cells. Virus Genes 2012 45(2):274-282.

4. Tang QH, Zhang YM, Fan L, Tong G, He L, Dai C: Classic swine fever virus NS2 protein leads to the induction of cell cycle arrest at S-phase and endoplasmic reticulum stress. Virol J 2010, 7:4.

5. Graham SP, Everett HE, Johns HL, Haines FJ, La Rocca SA, Khatri M, Wright IK, Drew T, Crooke HR: Characterisation of virus-specific peripheral blood cell cytokine responses following vaccination or infection with classical swine fever viruses. Vet Microbio/ 2010, 142(1-2):34-40.

6. Horst HS, de Vos CJ, Tomassen FH, Stelwagen J: The economic evaluation of control and eradication of epidemic livestock diseases. Rev Sci Tech 1999, 18(2):367-379.

7. Dionisio N, Garcia-Mediavilla MV, Sanchez-Campos S, Majano PL, Benedicto I, Rosado JA, Salido GM, Gonzalez-Gallego J: Hepatitis C virus NS5A and core proteins induce oxidative stress-mediated calcium signalling alterations in hepatocytes. J Hepatol 2009, 50(5):872-882.

8. Lim W, Kwon SH, Cho H, Kim S, Lee S, Ryu WS: HBx targeting to mitochondria and ROS generation are necessary but insufficient for HBV-induced cyclooxygenase-2 expression. J Mol Med (Berl) 2010, 88(4):359-369.

9. Israel N, Gougerot-Pocidalo MA: Oxidative stress in human immunodeficiency virus infection. Cell Mol Life Sci 1997, 53(11-12):864-870.

10. Gaudernak E, Seipelt J, Triendl A, Grassauer A, Kuechler E: Antiviral effects of pyrrolidine dithiocarbamate on human rhinoviruses. J Virol 2002, 76(12):6004-6015.

11. Schweizer M, Peterhans E: Oxidative stress in cells infected with bovine viral diarrhoea virus: a crucial step in the induction of apoptosis. J Gen Virol 1999, 80(Pt 5):1147-1155.

12. Venturini D, Simao AN, Barbosa DS, Lavado EL, Narciso VE, Dichi I, Dichi JB: Increased oxidative stress, decreased total antioxidant capacity, and iron overload in untreated patients with chronic hepatitis C. Dig Dis Sci 2010, 55(4):1120-1127.

13. Qadri I, Iwahashi M, Capasso JM, Hopken MW, Flores S, Schaack J, Simon FR: Induced oxidative stress and activated expression of manganese superoxide dismutase during hepatitis C virus replication: role of JNK, p38 MAPK and AP-1. Biochem J 2004, 378(Pt 3):919-928.

14. Bensaude E, Turner JL, Wakeley PR, Sweetman DA, Pardieu C, Drew TW, Wileman T, Powell PP: Classical swine fever virus induces proinflammatory cytokines and tissue factor expression and inhibits apoptosis and interferon synthesis during the establishment of long-term infection of porcine vascular endothelial cells. J Gen Virol 2004, 85(Pt 4):1029-1037.

15. Wang CY, Yeh HI, Chang TJ, Hsiao HJ, Tsai MS, Tsai SM, Liu PA: Attenuation of nitric oxide bioavailability in porcine aortic endothelial cells by classical swine fever virus. Arch Virol 2011, 156(7):1151-1160.
16. Forstermann U: Nitric oxide and oxidative stress in vascular disease. Pflugers Arch 2010, 459(6):923-939.

17. Finkel T, Holbrook NJ: Oxidants, oxidative stress and the biology of ageing. Nature 2000, 408(6809):239-247.

18. Okuda M, Li K, Beard MR, Showalter LA, Scholle F, Lemon SM, Weinman SA: Mitochondrial injury, oxidative stress, and antioxidant gene expression are induced by hepatitis C virus core protein. Gastroenterology 2002, 122(2):366-375.

19. Meyers G, Thiel HJ: Cytopathogenicity of classical swine fever virus caused by defective interfering particles. J Virol 1995. 69(6):3683-3689.

20. Johns HL, Bensaude E, La Rocca SA, Seago J, Charleston B, Steinbach F, Drew TW, Crooke $\mathrm{H}$, Everett $\mathrm{H}$ : Classical swine fever virus infection protects aortic endothelial cells from plpC-mediated apoptosis. J Gen Virol 2010, 91(Pt 4):1038-1046.

21. Knoetig SM, Summerfield A, Spagnuolo-Weaver M, McCullough KC: Immunopathogenesis of classical swine fever: role of monocytic cells. Immunology 1999, 97(2):359-366.

22. Yen YT, Chen HC, Lin YD, Shieh CC, Wu-Hsieh BA: Enhancement by tumor necrosis factor alpha of dengue virus-induced endothelial cell production of reactive nitrogen and oxygen species is key to hemorrhage development. J Virol 2008, 82(24):12312-12324.

23. Bengtsson AA, Pettersson A, Wichert $S$, Gullstrand B, Hansson M, Hellmark T, Johansson AC: Low production of reactive oxygen species in granulocytes is associated with organ damage in systemic lupus erythematosus. Arthritis Res Ther 2014, 16(3):R120.

24. Reshi ML, Su YC, Hong JR: RNA viruses: ROS-mediated cell death. Int J Cell Biol 2014, 2014:467452.

25. Kim YW, West $X Z$, Byzova TV: Inflammation and oxidative stress in angiogenesis and vascular disease. J Mol Med (Berl) 2013, 91(3):323-328.

26. Kim YW, Byzova TV: Oxidative stress in angiogenesis and vascular disease. Blood 2014, 123(5):625-631.

27. Forstermann U: Oxidative stress in vascular disease: causes, defense mechanisms and potential therapies. Nat Clin Pract Cardiovasc Med 2008, 5(6):338-349.

28. Kumagai Y, Pi J: Molecular basis for arsenic-induced alteration in nitric oxide production and oxidative stress: implication of endothelial dysfunction. Toxicol Appl Pharmacol 2004, 198(3):450-457.

29. Chen H, Montagnani M, Funahashi T, Shimomura I, Quon MJ: Adiponectin stimulates production of nitric oxide in vascular endothelial cells. J Biol Chem 2003, 278(45):45021-45026.

30. Li WG, Gavrila D, Liu X, Wang L, Gunnlaugsson S, Stoll LL, McCormick ML, Sigmund CD, Tang C, Weintraub NL: Ghrelin inhibits proinflammatory responses and nuclear factor-kappaB activation in human endothelial cells. Circulation 2004, 109(18):2221-2226.

31. Hanschmann EM, Godoy JR, Berndt C, Hudemann C, Lillig CH: Thioredoxins, glutaredoxins, and peroxiredoxins-molecular mechanisms and health significance: from cofactors to antioxidants to redox signaling. Antioxid Redox Signal 2013, 19(13):1539-1605.

32. Nordberg J, Arner ES: Reactive oxygen species, antioxidants, and the mammalian thioredoxin system. Free Radic Biol Med 2001, 31(11):1287-1312

33. Morin P Jr, Storey KB: Antioxidant defense in hibernation: cloning and expression of peroxiredoxins from hibernating ground squirrels. Spermophilus Tridecemlineatus Arch Biochem Biophys 2007, 461(1):59-65.

34. Haendeler J, Hoffmann J, Tischler V, Berk BC, Zeiher AM, Dimmeler S: Redox regulatory and anti-apoptotic functions of thioredoxin depend on S-nitrosylation at cysteine 69. Nat Cell Biol 2002, 4(10):743-749.

35. Fernandez-Sanchez A, Madrigal-Santillan E, Bautista M, Esquivel-Soto J, Morales-Gonzalez A, Esquivel-Chirino C, Durante-Montiel I, Sanchez-Rivera G, Valadez-Vega C, Morales-Gonzalez JA: Inflammation, oxidative stress, and obesity. Int J Mol Sci 2011, 12(5):3117-3132.

36. Reuter S, Gupta SC, Chaturvedi MM, Aggarwal BB: Oxidative stress, inflammation, and cancer: how are they linked? Free Radic Biol Med 2010 49(11):1603-1616.

37. Li S, Qu H, Hao J, Sun J, Guo H, Guo C, Sun B, Tu C: Proteomic analysis of primary porcine endothelial cells after infection by classical swine fever virus. Biochim Biophys Acta 2010, 1804(9):1882-1888.

38. Lee JC, Chen WC, Wu SF, Tseng CK, Chiou CY, Chang FR, Hsu SH, Wu YC: Anti-hepatitis $C$ virus activity of Acacia confusa extract via suppressing cyclooxygenase-2. Antiviral Res 2011, 89(1):35-42. 
39. Lanke K, Krenn BM, Melchers WJ, Seipelt J, van Kuppeveld FJ: PDTC inhibits picornavirus polyprotein processing and RNA replication by transporting zinc ions into cells. J Gen Virol 2007, 88(Pt 4):1206-1217.

40. Hong HX, Zhang YM, Xu H, Su ZY, Sun P: Immortalization of swine umbilical vein endothelial cells with human telomerase reverse transcriptase. Mol Cells 2007, 24(3):358-363.

doi:10.1186/s12917-014-0279-3

Cite this article as: He et al:: Classical swine fever virus induces oxidative stress in swine umbilical vein endothelial cells. BMC Veterinary Research 2014 10:279

\section{Submit your next manuscript to BioMed Central and take full advantage of:}

- Convenient online submission

- Thorough peer review

- No space constraints or color figure charges

- Immediate publication on acceptance

- Inclusion in PubMed, CAS, Scopus and Google Scholar

- Research which is freely available for redistribution 